\title{
DOSSIER
}

\section{PRÁCTICAS ECONÓMICAS HETERODOXAS, DECOLONIALIDAD Y ETNICIDAD. DOS EXPERIENCIAS MAPUCHE DE ECONOMIA SOCIAL EN ARGENIINA-2}

\section{HETERODOX ECONOMIC PRACTICES, DECOLONIALITY AND ETHNICITY. TWO MAPUCHE EXPERIENCES OF SOCIAL ECONOMY IN ARGENTINA}

\section{MARÍA GISELA HADAD ${ }^{3}$}

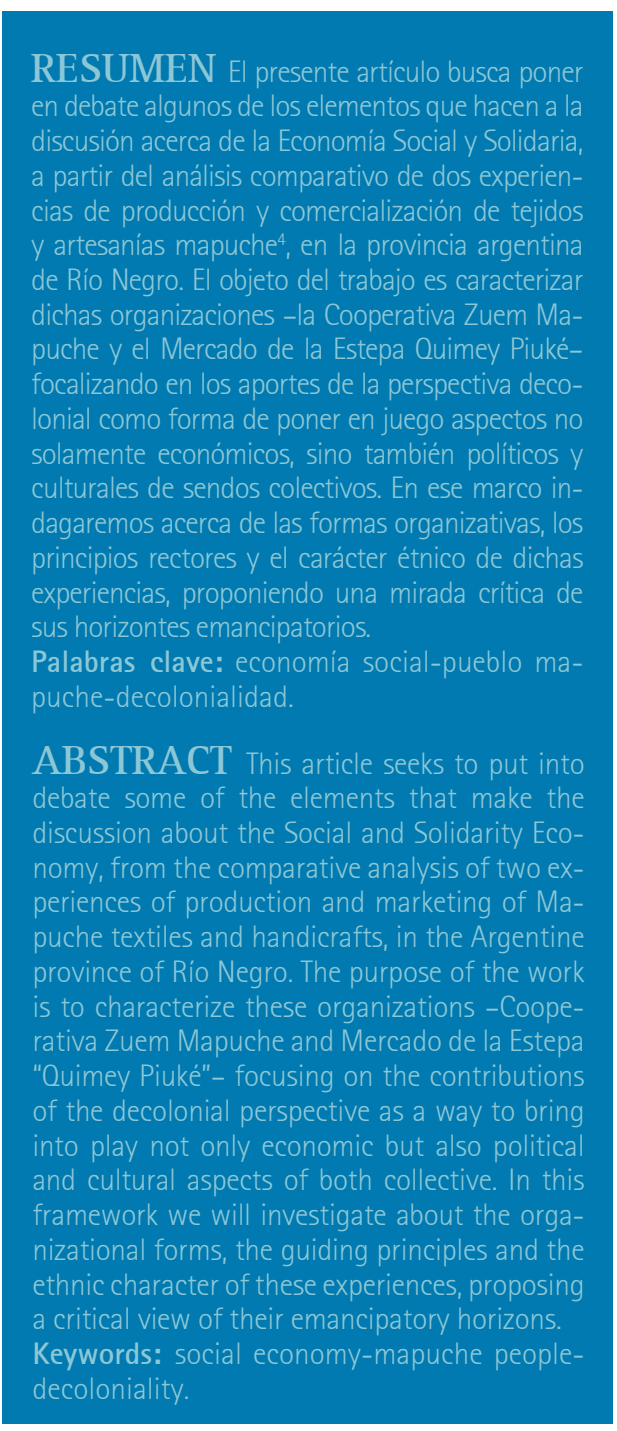

1 Trabajo enviado el 31 de mayo de 2018 y aprobado el 4 de agosto de 2018.

${ }^{2}$ Agradezco especialmente el asesoramiento bibliográfico de Luciana García Guerreiro para este artículo.

${ }^{3}$ Instituto de Investigaciones Gino Germani, Universidad de Buenos Aires-Conicet. Dra. en Ciencias Sociales (UBA), Magíster en Estudios Latinoamericanos (UCM, Madrid); Lic. y Prof. en Sociologia (UBA).Email: giselahadad@hotmail.com

${ }^{4}$ Siguiendo el uso de las comunidades y las convenciones académicas actuales, se emplea el singular mapuche que significa "gente de la tierra" en mapudungun (idioma mapuche), ya que es un sustantivo colectivo.

\section{INTRODUCCIÓN}

Aún bajo la pretensión totalizante de la economía de mercado en el sistema capitalista, históricamente se han conformado espacios de construcción alternativa de prácticas sociales, políticas y económicas. En particular, las grietas del orden económico hegemónico posibilitan aperturas donde las reglas del juego son heterogéneas y los principios rectores responden a lógicas otras de producción, intercambio y consumo. Las zonas marginales de la economía formal -materializadas en las más diversas formas y grados de autogestión, cooperación, horizontalidad y autonomía- son espacios que disputan los sentidos habituales del trabajo, el consumo y la reproducción de la vida, los cuales nos permiten, a partir de su análisis, ahondar en las concepciones profundas y constitutivas de comunidades y organizaciones que apuestan por una construcción societal alternativa.

La propuesta del presente trabajo es analizar comparativamente dos experiencias de producción y comercialización de productos tejidos, hilados y artesanías mapuche ${ }^{5}$, ubicadas en el departamento Bariloche, provincia de Río Negro (Argentina). Tanto la Cooperativa Zuem Mapuche como el Mercado de la Estepa Kimey Piuké, de ellos se trata, poseen una historia de varias décadas y se han conformado en espacios de expresión de la Economía Social en la zona. Sin embargo, ambas experiencias ofrecen rasgos disimiles en cuanto al sentido de la producción y el modo en que se presentan como colectivo. Mientras que en el primer caso la forma económica que se asume posee las características del cooperativismo y se inscribe en el marco de espacios comunitarios que poseen un alto perfil étnico; en el segundo, la etnicidad no es un factor que la atraviese visiblemente. De acuerdo con nuestra hipótesis, ambas organizaciones ofrecen similares productos y los mismos provienen de pobladores (tejedores, artesanos) ubicados en la misma región, mas su perfil organizacional discurre por caminos diversos, determinando que mientras un caso es decididamente una expresión de la deconstrucción identitaria y su posterior construcción desde la etnicidad, el otro se mantienen en un nivel de reivindicación de la justicia social y la economía 
De Prácticas y discursos

Universidad Nacional del Nordeste

Centro de Estudios Sociales

Año 7 , Número 10, 2018, Octubre

ISSN 2250-6942

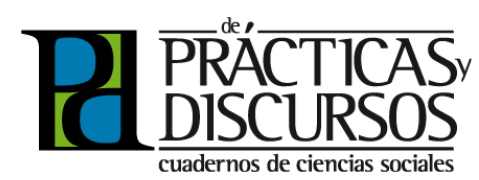

${ }^{5}$ Siguiendo el uso de las comunidades y las convenciones académicas actuales, se emplea el singular mapuche que significa "gente de la tierra" en mapudungun (idioma mapuche), ya que es un sustantivo colectivo.

${ }^{6}$ A pesar de existir cierta especificidad en el uso de la adjetivación "solidaria” del término economía con respecto al más genérico "economía social” -en el primer caso el énfasis está puesto en la generación de vínculos de solidaridad a través de prácticas de autogestión y la generación de acciones solidarias hacia la población más desfavorecida (Singer, 2007)-, a los fines de este trabajo no distinguiremos entre los mismos.

${ }^{7}$ De acuerdo con Quintero (2012), las primeras tendencias que procuraron pensar y poner en práctica formas económicas alternativas al sistema capitalista fueron contemporáneas a la consolidación del mismo. Ya en el siglo XIX se encuentran los primeros aportes teóricos que expresan la disconformidad con el liberalismo económico, encarnadas en el socialismo utópico de Owen, Fourier, Lassalle y Saint Simon. Posteriormente las contribuciones de Marx y Polanyi a la crítica del capitalismo constituyeron un sustrato prolífico desde donde autores como Coraggio, Singer y Razeto han abrevado para su construcción de la noción de Economía Social. solidaria, que parecería no cuestionar la colonialidad que implica seguir invisibilizando la cuestión étnica. Este y otros debates serán desarrollados a partir de la exposición de las particularidades de los casos en estudio, inspirados en la idea de que "es necesario (...) ubicar a la economía solidaria como parte de un todo mayor, en el proceso de reorganización de la sociedad sobre las bases de una racionalidad liberadora y solidaria" (Marañón, 2012: 46).

\section{LA ECONOMİA SOCIAL, APUNTES TEÓRICOS}

El análisis de las experiencias concretas de Economía Social propuesto en este trabajo nos remite a la conceptualización que de este tipo de prácticas se viene haciendo en los últimos años. Un primer punto de partida es el enmarcado de la Economía Social o Solidaria ${ }^{6}$ en el ámbito del estudio de las formas alternativas a la economía de mercado -capitalista- tal cual la conocemos ${ }^{7}$. En este sentido son enriquecedores los aportes de varios autores que han profundizado en la caracterización de esta dimensión de lo económico, entre los que destaco a José Luis Coraggio. Tomando algunos de sus trabajos (Coraggio, 2004, 2011, 2016) sobre la temática, me resulta esclarecedora una primera diferenciación en la cual se entiende a la Economía Social como aquella que se presenta como superadora del dualismo clásico entre una economía de mercado y una economía centralizada con planificación estatal, plateando la existencia de instancias intermedias, entre las que emergen las experiencias de Economía Social (Coraggio, 2011).

Coraggio (2004) señala que esta perspectiva económica introduce la dimensión social en un ámbito dominado por la razón utilitarista, la cual tiende a interpretar los comportamientos y decisiones económicas como exclusiva derivación del cálculo de costo-beneficio y el objetivo de la maximización de la ganancia. Como señala el autor, a partir de la obra de Karl Polanyi (1975), la economía es uno de los ámbitos que constituyen la realidad social, y junto con las dimensiones política y cultural conforman un complejo entramado de variables que determinan la acción social -la usual compartimentación disciplinaria y temática con fines analíticos no debería confundirnos acerca de esta situación. Volviendo al planteo de Coraggio, entendemos que

Al ver la economía como inseparable de la cultura, la Economía Social la mira como espacio de acción constituido no 
De Prácticas y discursos

Universidad Nacional del Nordeste

Centro de Estudios Sociales

Año 7, Número 10, 2018, Octubre

ISSN 2250-6942
PRÁCTICAS ECONÓMICAS HETERODOXAS, DECOLONIALIDAD Y ETNICIDAD. DOS EXPERIENGIAS MAPUCHE DE ECONOMİA SOCIAL EN ARGENTINA

HETERODOX ECONOMIC PRACTICES, DECOLONIALITY AND ETHNICITY. TWO MAPUCHE EXPERIENCES OF SOCIAL ECONOMY IN ARGENTINA

por individuos utilitaristas que buscan ventajas materiales, sino por individuos, familias, comunidades y colectivos de diverso tipo que se mueven dentro de instituciones decantadas por la práctica o acordadas como arreglos voluntarios, que actúan haciendo transacciones entre la utilidad material y los valores de solidaridad y cooperación, limitando (no necesariamente anulando) la competencia (2011: 44-45).

De este modo nos ubicamos en un campo de análisis en el que reconocemos el valor de los vínculos sociales, los lazos de solidaridad y de cooperación como motores de la actividad económica, lo cual no implica desconocer las finalidades intrínsecamente económicas y de reproducción de la vida que también poseen, pero sí visibilizar aquello que es negado, o bien relegado, en la concepción clásica de la economía y el mercado. Desde esta última perspectiva: "El individualismo y la competencia de todos contra todos es la regla para que el sistema funcione. La solidaridad entre actores es considerada una deseconomía nociva" (Coraggio, 2016: 18), lo cual es indicativo de lo disruptivo que puede ser para la lógica del capital una forma de organización económica cuyos motores sean del orden de lo social/cooperativo/solidario.

Siguiendo a Coraggio, tomamos como punto de partida la noción de Economía Social y Solidaria caracterizada como "un sistema histórico de instituciones, valores y prácticas (recurrentes, por costumbres, por eficacia comprobada, jurídicas...) mediante el cual cada comunidad, conjunto de comunidades o sociedad, organiza y coordina el proceso económico..." (2016: 18), donde el acento estaría puesto en el aspecto comunitario y autonómico de la organización económica. A su vez, el autor identifica distintos momentos que conforman el proceso: la producción de bienes y servicios -bajo una pluralidad de formas, con principios de complementariedad, cooperación y autogestión, y en el marco de una relación restitutiva entre el trabajo y la naturaleza-; la distribución y redistribución de la riqueza; el intercambio justo -entre personas, sectores y regiones-; el consumo responsable y la coordinación consciente y responsable del conjunto de instancias del proceso. $Y$ nos detendremos especialmente en los dos primeros momentos, que son aquellos en los que las organizaciones bajo estudio tienen mayor injerencia. Como se evidenciará en los siguientes apartados, la instancia de producción de los bienes que se comercializan tanto en la Cooperativa Zuem Mapuche como en el Mercado de la Estepa es central en tanto se la presenta como auto-organizada 
De Prácticas y discursos

Universidad Nacional del Nordeste

Centro de Estudios Sociales

Año 7, Número 10, 2018, Octubre

ISSN 2250-6942

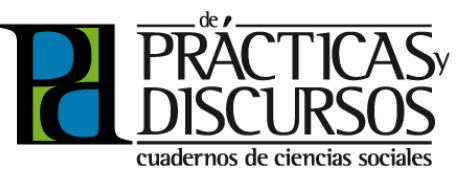

por los propios pobladores de la región en sus comunidades y unidades domésticas -y en algunos casos bajo regímenes de cooperativa. Desde el momento de la obtención de la materia prima principal -la lana de oveja-, pasando por el hilado y preparación para el tejido, hasta llegar a la comercialización de los productos terminados y la posterior distribución de la ganancia obtenida, todo el proceso estará signado por relaciones y lógicas que difieren -en mayor o menor medida- de la lógica de mercado.

Precisamente, la concurrencia al mercado es uno de los aspectos centrales de cualquier forma de producción y en términos generales, el predominio del carácter capitalista de los mercados es un sólido obstáculo con el que se encuentran las propuestas de formas alternativas de concebir la distribución y el consumo. Como es sabido, el mercado -en su concepción más primitiva- surge originalmente como un espacio donde se intercambian artículos de primera necesidad, en aparente igualdad de condiciones. Sin embargo, esta cándida imagen del mercado autoregulado y asignador natural de recursos y bienes es rápidamente cuestionada a partir del veloz avance de la industrialización y la expansión del comercio mundial, que dará lugar a la feroz crítica al sistema capitalista en su conjunto que inaugura Karl Marx (2008 [1867]). Sin embargo, la afamada "mano invisible" que mentaba Adam Smith (1990 [1776]) persistió como metáfora verosímil de la realidad, encontrándonos con que aún en la actualidad su presencia es hegemónica y su eficacia, poco cuestionada.

Sin embargo, como señala de Melo Lisboa (2004: 294),

Esta noción abstracta de mercado, en tanto un mecanismo auto-regulado a través de precios generados por el libre juego de la oferta y la demanda, no corresponde a la realidad de la economía moderna. Aún en los países capitalistas es imposible ignorar el papel fundamental de los elementos institucionales, de la herencia cultural y del contexto moral, de las relaciones de poder y los grados crecientes de monopolio que interfieren en los "automatismos", haciendo que gran parte de los precios [...] sea fijada administrativa y políticamente a partir de negociaciones no siempre transparentes.

Muchas experiencias de comercialización alternativas son críticas del rol del mercado y lo expresan en términos prácticos: sus acciones tienden a eludirlo en pos de relaciones más transparentes y directas entre productores y consumidores. Si entendemos el 
De Prácticas y discursos

Universidad Nacional del Nordeste

Centro de Estudios Sociales

Año 7, Número 10, 2018, Octubre

ISSN 2250-6942
PRÁCTICAS ECONÓMICAS HETERODOXAS, DECOLONIALIDAD Y ETNICIDAD. DOS EXPERIENGIAS MAPUCHE DE ECONOMİA SOCIAL EN ARGENTINA

HETERODOX ECONOMIC PRACTICES, DECOLONIALITY AND ETHNICITY. TWO MAPUCHE EXPERIENCES OF SOCIAL ECONOMY IN ARGENTINA

mercado exclusivamente como el espacio de maximización de la ganancia y de transformación de los bienes y servicios, del trabajo y el dinero en mercancía -con lo que esto implica-, sería esperable asumir una postura mercadofóbica (Melo Lisboa, 2004), pero el mercado es más que esto, es también un espacio de socialización y construcción de relaciones sociales, que permite la circulación y articulación de los más diversos actores. Por esta razón, nos parece propicia la distinción de Polanyi (en los términos de Melo Lisboa), según la cual: "La 'superación de la sociedad de mercado no significa, bajo ninguna forma, la ausencia de mercados', según lo afirma Polanyi, lo que nos lleva a diferenciar 'sociedad de mercado' de 'sociedad con mercado'" (2004: 300).

Este trabajo intentará, precisamente, interpretar algunas de las implicancias de dos espacios de comercialización que se organizan conjugando múltiples dimensiones de lo social y económico: lógica cooperativa, autogestión, principios de comercio justo, elementos de la identidad colectiva de las comunidades, relaciones de respeto y reciprocidad con la naturaleza, articulaciones políticas y otras tantas cuestiones, que aparecerán en una u otra, o en ambas organizaciones, permitiéndonos indagar acerca de la construcción de alternativas productivas y de reproducción de la vida de los sectores subalternos del orden social.

\section{LA ECONOMÍA SOCIAL COMO PRÁCTICA EMANCIPATORIA. UNA LECTURA DESDE LA PERSPECTIVA DECOLONIAL}

Como fuimos desarrollando precedentemente, el ámbito de la Economía Social y Solidaria abarca una gran diversidad de experiencias, actores e ideas. Dentro de los análisis posibles, la propuesta de iluminar el abordaje de las dos organizaciones barilochenses de comercialización de productos artesanales mapuche desde el enfoque decolonial -o de la colonialidad del poder- nos surge a partir de las lecturas clásicas que nutren dicha perspectiva. Autores como Aníbal Quijano, Edgardo Lander, Enrique Dussel, Arturo Escobar, Walter Mignolo y Ramón Grosfoguel, entre otros, son algunos de los principales exponentes de un paradigma conocido comúnmente como el grupo de estudios críticos de la colonialidad del saber (Lander, 2003), desde el cual esperamos alimentar el debate.

Siguiendo las precursoras ideas vertidas por Quijano (2003), América Latina es una construcción fundada sobre la base de 
De Prácticas y discursos

Universidad Nacional del Nordeste

Centro de Estudios Sociales

Año 7, Número 10, 2018, Octubre

ISSN 2250-6942

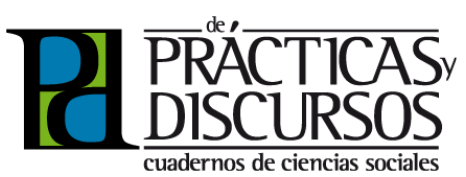

la idea de raza, entendida como una categoría que clasifica las diferencias en términos de desigualdad y perpetúa la jerarquía resultante a través de su naturalización. Según este autor, la histórica categorización genérica de los habitantes del continente en indios, negros, mestizos y europeos implica la determinación de su lugar en la estructura social y sus vínculos con los demás colectivos. Si bien los orígenes de la misma podrían encontrarse en las diferencias fenotípicas de unos y otros, el anclaje de las identidades emergentes a una escala de clasificación social representa el origen de la persistencia de la estructura de dominación colonial que regirá desde entonces, basada en una racionalidad específica, el eurocentrismo.

En una línea de continuidad con el pensamiento de Quijano, Mignolo (2007) desarrolla la idea de la "invención" de América Latina como crítica y superación del modelo eurocéntrico del "descubrimiento". Esta propuesta de transformación terminológica busca subvertir el relato histórico tradicional, planteando que la diferencia entre ambos vocablos implica la existencia de dos paradigmas interpretativos muy distintos. América es una invención porque su existencia no dependia de que fuera descubierta por los colonizadores. Evidentemente, América ya existía, así como también sus pobladores, aunque eran nominados de otro modo. Lo que no existía hasta ese entonces era la posibilidad de encontrar/construir "un otro" que por distintas razones -de orden económico, social, cultural y político- pudiera ser dominado e inducido a concebirse como inferior. Esta peculiaridad de la invención de América es el resultado de un proceso de construcción de hegemonía que determinó una transformación integral del orden mundial, en lo que Wallerstein (1979) caracteriza como la constitución del moderno sistema-mundo.

En este orden mundial, que es definido por Grosfoguel (2006) como intrínsecamente "moderno/colonial/capitalista/patriarcal", los sujetos se construyen jerárquicamente, y esta jerarquia es legitimada por el orden mundial eurocéntrico que la sustenta, construyendo una serie de pares dicotómicos que "explican" el devenir de la historia de la humanidad: Oriente-0ccidente (categorias que desbordan ampliamente la referencia a una ubicación geográfica), primitivo-civilizado, arcaico-moderno, irracional-racional, por mencionar los más recurrentes (Quijano, 2003). Europa y su población se (auto) sitúan en el extremo superior de esta suerte de escala evo- 
De Prácticas y discursos

Universidad Nacional del Nordeste

Centro de Estudios Sociales

Año 7, Número 10, 2018, Octubre

ISSN 2250-6942
PRÁCTICAS ECONÓMICAS HETERODOXAS, DECOLONIALIDAD Y ETNIIIDAD. DOS EXPERIENCIAS MAPUCHE DE ECONOMÍA SOCIAL EN ARGENTINA

HETERODOX ECONOMIC PRACTICES, DECOLONIALITY AND ETHNICITY. TWO MAPUCHE EXPERIENCES OF SOCIAL ECONOMY IN ARGENTINA

lutiva del desarrollo de la humanidad, confiriendo al resto del mundo distintas posiciones de mayor o menor cercanía al cenit de desarrollo deseado. Y en este complejo proceso de clasificación que incluye la puesta en marcha de un vasto entramado de ideas y valoraciones, la noción de raza tiene una gran fuerza performativa, constituyéndose como central en la determinación de las relaciones de dominación.

Uno de los elementos que comúnmente queda invisibilizado en este proceso de conformación del orden mundial es el rol determinante de la existencia de América en la definición de la modernidad. Podría decirse, siguiendo a Quijano (2003), que el patentamiento de la idea de modernidad que se arroga Europa es uno de sus más exitosos ejercicios de poder. Señala este autor que, si se acepta el supuesto de que moderno es un atributo que define lo último, lo avanzado, lo laico-secular, lo racional-científico, este tipo de experiencias culturales pueden encontrarse a lo largo de la historia en todas las Ilamadas altas culturas. El triunfo de la racionalidad eurocéntrica fue establecer con éxito la idea de que lo único moderno que existe es ella misma, por lo que, a partir de alli, el resto del mundo está "condenado" a seguir sus pasos para alcanzar el grado más alto de desarrollo y evolución posibles. Por esta razón, puede afirmarse que la entrada en la escena mundial de América a partir del siglo XVI implicó una transformación total del propio mundo, dado que Europa necesitó de su existencia material y simbólica para establecer el ordenamiento jerárquico que la posiciona en el estamento superior. Sin embargo, este proceso es enmascarado bajo la inocua idea de una modernidad objetiva, dado que, como dice Mignolo (2007: 61), "el mundo es, en apariencia, lo que las categorias europeas de pensamiento (...) permiten decir que es".

Por otro lado, se puede afirmar que la disposición de los sujetos y la forma en que se configuran las relaciones de poder en el orden mundial tienen su principal correlato en las relaciones económicas resultantes, pero no acaba allí. La división social del trabajo a escala mundial -con Estados constituidos como economías centrales y Estados periféricos que producen bienes en función de las necesidades de estas economías- es quizás la principal evidencia de las relaciones de dominación establecidas a partir de la época colonial, pero la construcción de los sujetos como subalternos per se, la idea de una superioridad natural de 
De Prácticas y discursos

Universidad Nacional del Nordeste

Centro de Estudios Sociales

Año 7, Número 10, 2018, Octubre

ISSN 2250-6942

\begin{abstract}
${ }^{8}$ Este grupo forma parte del Programa de Grupos de Trabajo (GT) del Consejo Latinoamericano de Ciencias Sociales (Clacso), donde equipos interdisciplinarios de distintos países profundizan en el estudio de los más diversos tópicos concernientes a las ciencias sociales de la región.
\end{abstract}

${ }^{9}$ Las organizaciones que analizaremos fueron dos de los casos seleccionados en el marco de la tesis doctoral titulada: "Lucha por la identidad y el territorio indígena. Dinámicas urbano-rurales y articulaciones intergeneracionales en la construcción identitaria del pueblo mapuche (Región Andina de Río Negro, 1992-2012)", del Programa de Doctorado en Ciencias Sociales de la Universidad de Buenos Aires, defendida en marzo de 2016. Los testimonios aqui presentes fueron recogidos en varios trabajos de campo realizados por la autora entre 2007 y 2013.

${ }^{10}$ Las organizaciones que analizaremos fueron dos de los casos seleccionados en el marco de la tesis doctoral titulada: "Lucha por la identidad y el territorio indígena. Dinámicas urbano-rurales y articulaciones intergeneracionales en la construcción identitaria del pueblo mapuche (Región Andina de Río Negro, 1992-2012)”, del Programa de Doctorado en Ciencias Sociales de la Universidad de Buenos Aires, defendida en marzo de 2016. Los testimonios aquí presentes fueron recogidos en varios trabajos de campo realizados por la autora entre 2007 y 2013. ciertos sectores de la humanidad en detrimento de otros que aún no han alcanzado esa instancia de "desarrollo", es quizás la más difícil de deconstruir. Como señala Ceceña (2004: 40):

la dominación no sólo se impone a través de los sistemas productivos, de los movimientos de la moneda o de las invasiones militares. La dominación se reproduce en lo cotidiano y en la creación de sentidos comunes que perciben y reproducen las relaciones sociales como relaciones de poder.

A partir de esto podemos comenzar a pensar la Economía Social precisamente como una forma alternativa a la visión modernal colonial/capitalista/patriarcal de la producción y el consumo. Señala Marañón-Pimentel (2012), coordinador del Grupo de Estudios de Economías alternativas y Buen Vivir de $\mathrm{Clacso}^{8}$, que la decolonialidad pone en evidencia la existencia de otras miradas sobre nuestra existencia social, visibilizando la artificialidad de la separación sujeto-objeto, hombre/mujer-naturaleza, culturanaturaleza, etc., y superando la preeminencia de la racionalidad instrumental, en pos de formas otras de organizar la vida, del orden de lo cooperativo-solidario. En este sentido, las experiencias de Economía Social desafían los preceptos de la racionalidad moderna capitalista, y no solo en lo que respecta a la dimensión económica. Precisamente, como señala García Guerreiro (2012: 184), "para pensar y practicar otras economías es necesario partir de otros pensamientos, que den cuenta de aquello que hoy es invisibilizado". A partir de todas estas ideas podemos ir pensando los casos que nos interesa considerar aquí.

\section{DOS EXPERIENCIAS DE ECONOMÍA SOCIAL EN LA PATAGONIA}

Llegados a este punto quisiéramos reflexionar en torno a dos experiencias concretas de economía solidaria en la Patagonia argentina, que fueron elegidas por su trayectoria en la zona, su alta visibilidad y sus caracteristicas diferenciadoras ${ }^{9}$. La primera de las organizaciones, la Cooperativa Zuem Mapuche, es un espacio de comercialización de productos mapuche en pleno centro de la ciudad de San Carlos de Bariloche ${ }^{10}$. La misma remonta sus orígenes a 1984, año en el que una gran nevada azotó la región y generó una situación de emergencia en la zona, dando inicio también al surgimiento de otras organizaciones de 
De Prácticas y discursos

Universidad Nacional del Nordeste

Centro de Estudios Sociales

Año 7, Número 10, 2018, Octubre

ISSN 2250-6942
PRÁCTICAS ECONÓMICAS HETERODOXAS, DECOLONIALIDAD Y ETNICIDAD. DOS EXPERIENCIAS MAPUCHE DE ECONOMÍA SOCIAL EN ARGENTINA

HETERODOX ECONOMIC PRACTICES, DECOLONIALITY AND ETHNICITY. TWO MAPUCHE EXPERIENCES OF SOCIAL ECONOMY IN ARGENTINA
${ }^{11}$ El Consejo Asesor Indígena es una de las principales organizaciones mapuche en la Argentina, con gran influencia en la provincia de Río Negro.

\footnotetext{
${ }^{12}$ La zona denominada Línea Sur comprende a los departamentos rionegrinos atravesados por la línea de ferrocarril Roca -Pilcaniyeu, Valcheta, 25 de Mayo, Ñorquinco, 9 de Julio, Avellaneda y El Cuy-, en su recorrido uniendo las ciudades de Bariloche y San Antonio Oeste, ambos extremos de la provincia. La región tiene una extensión aproximada de $114593 \mathrm{~km} 2$ y representa el 56,4\% de la superficie provincial.
}

${ }^{13}$ Por cuestiones de privacidad, los nombres de los entrevistados fueron modificados, manteniéndose la referencia a la organización a la que pertenecen.

14 Véase "Historia", de Cooperativa Zuem Mapuche (2014). base étnica, como el Consejo Asesor Indígena (CAI) ${ }^{11}$. Según los testimonios de algunos de sus miembros y fundadores, esta organización surge con la finalidad de mejorar las condiciones de producción y comercialización de los mapuche de la zona rural, fundamentalmente de la Línea Sur ${ }^{12}$.

la cooperativa tiene una trayectoria de muchos años, empezó a trabajar más o menos en el 83, 84. Y se formaron... o sea, la gente en el campo siempre tejía, hilaba, pero le costaba mucho la comercialización. Y bueno, después se empezó a organizar y a tratar de vender en la ciudad. Entonces se armaron grupos de colaboradores en Bariloche que vendían. Pero por ahí no era suficiente como siempre, cuando vos no sos parte de algo, es que lo hacés por colaborar, pero no tenés una obligación. Entonces en el año... 1990 más o menos hemos decidido que sean las mismas artesanas las que atiendan el local de ventas. Entonces armamos un grupo acá en Bariloche con descendientes de mapuches, gente que tiene relación con el campo y somos esas personas las que administramos y atendemos (María, miembro de la Cooperativa) ${ }^{13}$.

Uno de los fundadores de la cooperativa cuenta que las primeras experiencias de este tipo de organizaciones en la zona se dan en los años 60, y que de alli se extrajo la idea y la práctica de crear este colectivo que, a su vez, en un principio, eran tres cooperativas de Maquinchao, Ing. Jacobacci y Comallo (ciudades dentro de la región Línea Sur) Ilamadas respectivamente Peñiwen, Artesanal Mapuche y Nehuenche. Según lo que la organización cuenta en su blog ${ }^{14}$ y la información extraída de las entrevistas realizadas en el lugar, el objetivo prioritario era la posibilidad de organizarse para defender sus derechos y sus intereses comerciales, habida cuenta de que los pobladores del campo solian malvender sus productos a los comisionistas del lugar. Cuando la situación crítica de 1984 se presenta, con la experiencia de otras cooperativas de años anteriores y el patrocinio de distintas instituciones como la Iglesia -a través del obispo de Viedma, Monseñor Miguel Hesayne-, la ONG Misereor -institución de cooperación internacional perteneciente a la Iglesia católica alemana- y, posteriormente, la ONG Manos Unidas (España), los pobladores se reorganizan y constituyen esta instancia de venta directa de productos del campo.

La Cooperativa Zuem Mapuche se dedica específicamente a la venta de tejidos elaborados con lanas naturales de oveja, guana- 
De Prácticas y discursos

Universidad Nacional del Nordeste

Centro de Estudios Sociales

Año 7, Número 10, 2018, Octubre

ISSN 2250-6942

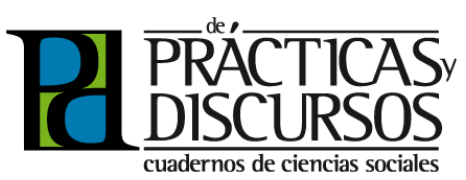

${ }^{15}$ El Mercado de la Estepa Quimey Piuké funciona en un predio cedido en concesión por la Municipalidad de Dina Huapi a la Asociación Surcos Patagónicos, y está ubicado en la intersección de las rutas nacionales 40 y 23. co y chivo, hiladas en forma manual, y sus productos provienen de una red de aproximadamente 70 tejedoras de diversos poblados y parajes de la Línea Sur y alrededores: Comallo y Pilcaniyeu del Limay (departamento de Pilcaniyeu), Ing. Jacobacci y Maquinchao (departamento de 25 de Mayo), Chacay Huarruca y Río Chico (Ñorquinco), Mallín Ahogado (El Bolsón) y Bariloche, son los pueblos y ciudades mencionados por los entrevistados. Pero muchas de las familias viven en los campos aledaños y se acercan a estos lugares para entregar sus trabajos.

Una de las caracteristicas particulares de esta organización es su marcada referencia a la etnicidad. Ya desde su mismo nombre que contiene un término en mapudungun -zuem, que significa "hacer"- se ubica en la postura de asumir y representar la identidad mapuche. En sus propios fundamentos la cooperativa prioriza formas de producción propias de la cultura mapuche -hilados artesanales, teñidos naturales, diseños característicospor sobre otras producciones, entendiendo que esto es lo propio de su "hacer", y quieren mantenerse fieles a esto.

Esta organización no es la única que comercializa productos artesanales de origen mapuche en la zona. Recorriendo un poco más los alrededores de la ciudad de Bariloche, nos encontramos con un lugar que a simple vista es similar a la cooperativa. El Mercado de la Estepa Quimey Piuké, de él se trata, surge en 1999, a partir de la idea de un grupo de vecinos de Dina Huapi -un poblado perteneciente al departamento de Pilcaniyeu, a escasos $15 \mathrm{~km}$ de Bariloche- que decide fundar, por iniciativa de un ex sacerdote palotino, Roberto Killmeate, la Asociación Civil Surcos Patagónicos, de la cual forma parte el Mercado ${ }^{15}$. De acuerdo con los testimonios, esta organización tiene por objeto el fomento de la actividad rural sustentable, a partir de la comercialización de los productos realizados por los pobladores de la zona de la estepa rionegrina, fundamentalmente del departamento de Pilcaniyeu (se mencionan los poblados de Anecón Grande, Cañadón Chileno, Comallo, Nirihuau, Pilcaniyeu, Pilcaniyeu del Limay, Villa Llanquín, entre otros), y también llegan trabajos desde la lejana localidad de Valcheta (departamento homónimo) y la zona de la Meseta de Somuncurá.

El Mercado es un espacio de comercialización donde se evidencia el trabajo de pobladores mapuche, en tanto sus tejidos y sus materiales son similares a los que encontramos en la Cooperativa Zuem Mapuche. Sin embargo, los fundamentos de este empren- 
De Prácticas y discursos

Universidad Nacional del Nordeste

Centro de Estudios Sociales

Año 7, Número 10, 2018, Octubre

ISSN 2250-6942
PRÁCTICAS ECONÓMICAS HETERODOXAS, DECOLONIALIDAD Y ETNICIDAD. DOS EXPERIENCIAS MAPUCHE DE ECONOMÍA SOCIAL EN ARGENTINA

HETERODOX ECONOMIC PRACTICES, DECOLONIALITY AND ETHNICITY. TWO MAPUCHE EXPERIENCES OF SOCIAL ECONOMY IN ARGENTINA

\footnotetext{
${ }^{16}$ Se recogieron folletos explicativos en el lugar y se consultó el blog del Mercado de la Estepa, http://mercadodelaestepa.blogspot.com.ar/; y de la Asociación Surcos Patagónicos, http://surcospatagonicos.com.ar/historia.html
}

dimiento son distintos, ya que, al decir de su principal referente y fundador, los mueve específicamente el ideario de la Economía Social y Solidaria (Killmeate y Schulz, 2014).

De este modo, de acuerdo con los testimonios recogidos en las entrevistas y otras fuentes ${ }^{16}$, la orientación de este emprendimiento se define por su finalidad de generar relaciones productivas más justas que las convencionales, que retribuyan al productor un monto que le permita reproducir su vida y la de los suyos. También se busca que los vínculos que se generen a partir de este tipo de intercambios se basen en valores y pautas solidarias, que hagan primar lo social de la relación por sobre lo económico. De este modo, el objetivo del Mercado de la Estepa es promover la producción rural y artesanal de los habitantes de los poblados de su zona de influencia, incentivando las vinculaciones respetuosas en una suerte de ética responsable y fraterna.

Como mencioné desde un principio, a primera vista la experiencia de la Cooperativa y del Mercado parecen similares, en tanto los productos que comercializan lo son. Sin embargo, tanto los procesos que generaron su creación, como los principios y fundamentos de su existencia, presentan importantes diferencias. La Cooperativa Zuem Mapuche tiene un surgimiento cercano a la autogestión, donde los propios interesados toman la iniciativa de organizarse frente a un evento adverso como fue lo ocurrido en 1984. Si bien puede entreverse que la experiencia previa de algunos de los referentes en lo que refiere a gestión cooperativa fue determinante, y que además contaron con el fundamental auspicio de entidades externas, como la Iglesia y las ONG, los referentes fueron miembros del pueblo mapuche, cuya mirada colectiva de la situación les condujo a ver la necesidad de contar con una instancia de organización para mejorar sus condiciones de vida. En el caso del Mercado de la Estepa, está claro desde el comienzo que la iniciativa no es de los propios pobladores mapuche. Por el contrario, fueron algunos vecinos de la zona de Dina Huapi junto con Killmeate quienes se trasladaron al campo para comunicar su proyecto y lograr adhesiones:

se empezó pidiendo el terreno, y se empezó todo por el tema de que a la gente del campo la estaban explotando. Le daban por... un poncho de esos, le cambiaban por un saco de harina. Entonces hay gente que es vidente (sic), que es muy vidente, y vieron que los estaban explotando, y bueno, le dijeron no, bueno, vamos a ver qué es lo que vamos a hacer. 
De Prácticas y discursos

Universidad Nacional del Nordeste

Centro de Estudios Sociales

Año 7, Número 10, 2018, Octubre

ISSN 2250-6942

\begin{abstract}
${ }^{17}$ Los principios del cooperativismo pueden resumirse en: adhesión voluntaria y libre acceso; base democrática de organización; limitación del interés al capital; distribución de excedente; promoción de la educación e integración cooperativa (extraído de los principios de la Alianza Cooperativa Internacional (ACl), citado en Vuotto, 1994).

${ }^{18}$ El Comercio Justo implica un proceso de intercambio más equitativo y respetuoso entre productores y consumidores, que apunta al desarrollo de los sectores más marginales de la economía a escala mundial. Sus supuestos se basan en la necesidad de establecer condiciones justas de producción y comercialización que permitan la reproducción digna de la vida de los sectores empobrecidos. Como señalan Cotera y Ortiz Roca (2009: 77): "El comercio justo puede definirse como la relación de 'intercambio' económico y ético entre productores responsables y consumidores éticos, orientados hacia el desarrollo humano solidario e integral".
\end{abstract}

\begin{abstract}
Entonces [la Asociación Civil] Surcos, que en ese momento era la que estaba, empezó a movilizarse en el campo, a ir a los parajes, a conversar con la gente, a decirle lo que pensaban ellos hacer, y a ver si la gente se interesaba como para, viste, traer sus productos acá... (Entrevista a Cristina, productora en el Mercado de la Estepa).
\end{abstract}

Más allá de que los fines fueran similares, la forma en que se gesta la organización condiciona el devenir de la misma, dado que como se verá en el tiempo, en el caso de la Cooperativa las decisiones son mucho más consensuadas y horizontales que en el Mercado: tanto la forma de dirigir la organización -con autoridades elegidas por los mismos miembros, con mandatos temporales y un esquema de gestión inspirado en la práctica cooperativista ${ }^{17}$ - como la determinación de los medios y fines de la misma, competen al colectivo y como tal, lo llevan a cabo. Por su parte, el Mercado deja en manos de "la gente de Surcos" muchos de los aspectos de la gestión y administración, pareciendo ser la participación de los pobladores/productores reducida a la manufactura de los productos y la atención del local de venta los fines de semana.

Vinculado con esto, los principios que guian cada una de las organizaciones a nivel de su funcionamiento y su propia lógica son similares, aunque se remiten formalmente a distintas fuentes. Mientras la Cooperativa Zuem Mapuche se rige por los principios cooperativistas, el Mercado de la Estepa prioriza la lógica del llamado "Comercio Justo". Si bien ambas perspectivas son cercanas en algunos aspectos, en el primer caso el acento está puesto en la organización de los trabajadores, la autogestión y la participación plena y democrática de los miembros en cada aspecto del proceso productivo y comercial. En el segundo caso, el mayor énfasis está puesto en los vínculos de equidad, solidaridad y responsabilidad social, que no son contrarios a los del cooperativismo, solo que enfatizan en otras cuestiones ${ }^{18}$. En la práctica, el discurso de los miembros de la Cooperativa es más horizontal y autonómico, y denota mayor compromiso con cada paso de la producción que el de los miembros del Mercado, que evidencian no conocer muchos de los aspectos de su funcionamiento. Si bien ambas perspectivas están emparentadas, las sutiles diferencias entre ambas se condicen con lo que arrojan los discursos de los entrevistados.

Por otro lado, la cuestión de la etnicidad es un elemento de diferenciación fundamental entre ambas organizaciones. Siguiendo 
De Prácticas y discursos

Universidad Nacional del Nordeste

Centro de Estudios Sociales

Año 7, Número 10, 2018, Octubre

ISSN 2250-6942
PRÁCTICAS ECONÓMICAS HETERODOXAS, DECOLONIALIDAD Y ETNICIDAD. DOS EXPERIENCIAS MAPUCHE DE ECONOMÍA SOCIAL EN ARGENTINA

HETERODOX ECONOMIC PRACTICES, DECOLONIALITY AND ETHNICITY. TWO MAPUCHE EXPERIENCES OF SOCIAL ECONOMY IN ARGENTINA

a Bartolomé, consideramos a la etnicidad como la expresión de la identidad étnica organizada con fines políticos $y$, al mismo tiempo, la estructuración ideológica -que el autor llama conciencia étnica- de los elementos culturales que definen al grupo. La misma se vincula estrechamente con la identidad del colectivo en cuestión, pero implica un paso más en la visibilización de los conflictos y las reivindicaciones. Dice el autor que

Cuando la identidad de un grupo étnico se configura orgánicamente como expresión de un proyecto social, cultural y/o político que supone la afirmación de lo propio en clara confrontación con lo alterno, nos encontramos en presencia de la etnicidad. La etnicidad se manifiesta entonces como la expresión y afirmación protagónica de una identidad étnica específica. (1997: 62. El destacado en el original)

Esta caracterización deja en evidencia dos cuestiones fundamentales: por un lado, que la etnicidad, es decir, el asumir la organización de las diferencias culturales con una finalidad política, debe considerarse en forma paralela pero independiente de la identidad, ya que, aunque ambas compartan los rasgos culturales del grupo, son instancias independientes. Por otro lado, se evidencia que la sola existencia de una identidad étnica no supone la organización política del grupo social en cuestión, puesto que como se desprende de la definición de Bartolomé, solo algunos grupos étnicos avanzan en esa dirección.

La Cooperativa Zuem Mapuche enuncia desde su nombre la adscripción étnica. El Mercado de la Estepa, si bien se llama Quimey Piuké, "corazón bello", y refiere a un nombre en mapudungun como muchísimas entidades comerciales en la Patagonia que utilizan nombres en dicho idioma como parte del folclore- no hace mayores referencias a la cuestión indígena en su presentación al público y en su propio local de ventas. En las entrevistas con miembros de ambas organizaciones se indagó sobre los aspectos vinculados con la pertenencia étnica y la organización mapuche, inquiriendo acerca de si los miembros de las mismas formaban parte de alguna comunidad mapuche o se identificaban como tales, si tenían reivindicaciones como colectivo o alguna forma de representación a nivel político. Las respuestas fueron coherentes con la imagen que cada una de las organizaciones proyecta hacia afuera: en el caso de la Cooperativa, su propio origen 
De Prácticas y discursos

Universidad Nacional del Nordeste

Centro de Estudios Sociales

Año 7, Número 10, 2018, Octubre

ISSN 2250-6942

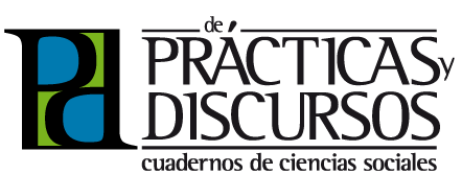

habla de pertenencia al pueblo mapuche. Su inicial vinculación con el CAl también es una evidencia de la importancia que se le da a la cuestión, siendo una de las finalidades enunciadas la de promover el desarrollo y ayudar al sostenimiento de la poblaciones mapuche del campo. Por su parte, las entrevistas realizadas en el Mercado a varios de sus miembros -tanto los que viven en Dina Huapi como los que vienen del "campo" a atender el local los fines de semana- dieron como resultado muy vagas referencias a la etnicidad. En general, la única mención espontánea fue para decir que se tejía con técnicas de telar mapuche, pero no se asoció esto, en ningún momento, con la identidad étnica de las poblaciones que realizan los trabajos. Permanentemente se habló de los sujetos como "pobladores" o "gente del campo" y de los lugares de procedencia como pueblos y parajes de la meseta, nunca como mapuche o comunidades. La omisión no necesariamente implica, a mi entender, la finalidad de ocultar la etnicidad, sino más bien la no relevancia que se le da en este contexto. Es decir, que las producciones sean realizadas por mapuche y según técnicas mapuche de producción, no es un dato que a las personas entrevistadas les interesara destacar. Y Ilamativamente, tampoco se menciona en el artículo escrito por Killmeate y Schulz (2014) acerca del emprendimiento que ayudara a fundar. Coherentemente con esto, la organización política de las comunidades no es un tema presente en el discurso de los miembros del Mercado. Ante la pregunta directa, la respuesta es que no tienen conocimiento de este tipo de organización, o de cualquier forma de organización en términos de etnicidad, de la gente que forma parte del Mercado. En este sentido, las personas entrevistadas en la Cooperativa mostraron mayor interés por la temática y conocimientos al respecto, vinculando las actividades que ellos realizan allí, con la lucha mapuche por el territorio y la defensa cultural. Así, los productos a la venta en esta última son cuidadosamente seleccionados sobre la base de criterios de autenticidad respecto de los métodos y materiales mapuche. Por su parte, en el Mercado es posible encontrar una serie de producciones no necesariamente identificables con la cultura mapuche, provenientes de vecinos de las cercanías y hasta de alumnos de las escuelas de la zona, que efectivamente evidencian que no es la única prioridad la producción de este tipo.

Todos los aspectos mencionados hasta acá nos permiten arribar a ciertas conclusiones respecto de la identidad étnica de las or- 
De Prácticas y discursos

Universidad Nacional del Nordeste

Centro de Estudios Sociales

Año 7, Número 10, 2018, Octubre

ISSN 2250-6942
PRÁCTICAS ECONÓMICAS HETERODOXAS, DECOLONIALIDAD Y ETNICIDAD. DOS EXPERIENGIAS MAPUCHE DE ECONOMİA SOCIAL EN ARGENTINA

HETERODOX ECONOMIC PRACTICES, DECOLONIALITY AND ETHNICITY. TWO MAPUCHE EXPERIENCES OF SOCIAL ECONOMY IN ARGENTINA

ganizaciones. Por una parte, ambos colectivos llevan a cabo una labor similar en tanto comercializan elementos realizados por productores independientes -en muchos casos nucleados formando asociaciones en sus lugares de procedencia- que provienen de una misma zona o de sus cercanías. Las similitudes entre los tejidos, las lanas no laboreadas y los cueros que una y otra entidad ofrecen son enormes. Podría decirse que los productos, sin entrar en detalles, son semejantes. Y probablemente los territorios de procedencia también lo sean, ya que ambas organizaciones mencionan los mismos pueblos y parajes como lugares de origen de sus productos. De este modo, lo que sería distinto es el tipo de organización que los nuclea en la ciudad para la venta de sus artículos, y en este sentido, sus diferencias y similitudes ya fueron expuestas. Por lo tanto, nos encontramos con una organización, la Cooperativa Zuem Mapuche, que reivindica la etnicidad como forma de vincularse con la sociedad no indígena que la rodea, haciendo de ella un valor y una característica única y reivindicable por sus valores intrínsecos. Por otro lado, vemos una organización, el Mercado de la Estepa que, a pesar de abrevar en las mismas fuentes, no lo hace visible ni discursiva, ni materialmente. Nada en su discurso lo menciona, y en el lugar de venta tampoco se observan elementos que identifiquen a las poblaciones como mapuche: no hay banderas, no hay menciones en la cartelería, ni aparece la palabra "mapuche" en ningún lado. Paradójicamente, los carteles sí hablan de identidad, destacando la identificación de las comunidades con la Estepa, es decir, con

el espacio definido por la geografía física. Dice allí:

\section{"Identidad"}

Generamos espacios de encuentro y trabajo para difundir la realidad de nuestras comunidades.

A través de actividades productivas, culturales y artísticas afianzamos los valores e historia de la Estepa y su gente.

Buscamos así sostener nuestra forma de vida, nuestra cultu$r a$, en nuestra región de origen.

Como se ve, bien podría mencionarse alli el origen mapuche de las comunidades o alguna referencia al respecto. Sin embargo, se habla de comunidades sin más menciones, de cultura y forma de vida, de 
De Prácticas y discursos

Universidad Nacional del Nordeste

Centro de Estudios Sociales

Año 7, Número 10, 2018, Octubre

ISSN 2250-6942

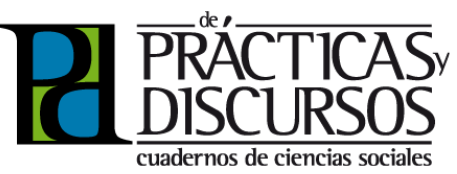

historia y de valores, pero vacíos de contenido. Es una omisión que llama poderosamente la atención si se tienen en cuenta los datos contextuales de los lugares de procedencia de los productos.

En los casos descriptos, tanto la Cooperativa Zuem Mapuche como el Mercado de la Estepa son dos experiencias que reflejan la vinculación de poblaciones mapuche rurales a un espacio urbano, manteniendo sus características identitarias. Los productores que se nuclean en la Cooperativa tienen una adscripción étnica visible y hacen de ella una fortaleza. Se diferencian positivamente desde esta postura identitaria. Los productores asociados al Mercado posiblemente tengan también una adscripción étnica a nivel personal o colectivo, pero esta no se refleja en la organización. Y nos permitimos inferir esto de las observaciones y entrevistas realizadas, dado que las producciones que realizan, la forma de llevarlas a cabo, los lugares de procedencia y demás, como ya hemos mencionado, son similares al primer caso. Veremos ahora, finalmente, qué relevancia tienen estas diferenciaciones en términos de una práctica económica alternativa y emancipadora, tal como la explicitamos anteriormente.

\section{LA ECONOMÍA SOCIAL COMO PRAXIS DECOLONIAL. UNA APUESTA POR LA EMANCIPACIÓN DE LOS PUEBLOS}

Los casos que fuimos relatando son experiencias de producción y comercialización que se inscriben en la lógica de la Economía Social. En ambas prácticas encontramos elementos que nos revelan la presencia de estrategias que no siguen los principios de la racionalidad instrumental, o por lo menos, no exclusivamente. Sustraerse del mercado y su pretensión de universalidad no es sencillo, dada su masiva penetración y su capacidad de reinversión y de adaptarse a los más diversos contextos. Sin embargo, estamos de acuerdo con Coraggio (2011: 45) cuando señala que: "Se trata de poner límites sociales al mercado capitalista y, si es posible, construir mercados donde los precios y las relaciones resultan de una matriz social que pretende la integración de todos con un esfuerzo y unos resultados distribuidos de manera más igualitaria". Al tratarse de organizaciones que suponen un respeto por las condiciones de producción -en términos de garantizar la reproducción de la vida- y que generan condiciones de participación y autonomía en la gestión de la actividad, entendemos que responden a los criterios que fuimos mencionando para ca- 
De Prácticas y discursos

Universidad Nacional del Nordeste

Centro de Estudios Sociales

Año 7, Número 10, 2018, Octubre

ISSN 2250-6942
PRÁCTICAS ECONÓMICAS HETERODOXAS, DECOLONIALIDAD Y ETNICIDAD. DOS EXPERIENGIAS MAPUCHE DE ECONOMİA SOCIAL EN ARGENTINA

HETERODOX ECONOMIC PRACTICES, DECOLONIALITY AND ETHNICITY. TWO MAPUCHE EXPERIENCES OF SOCIAL ECONOMY IN ARGENTINA

racterizar procesos económicos alternativos.

No obstante, la propuesta presentada desde la perspectiva decoIonial nos supone el desafío mayor de pensar y anclar las prácticas económicas en la dimensión política, y al hacerlo, tomar como núcleo la crítica al modelo en su totalidad. Eso impone la necesidad de mantener una postura que visualice y deconstruya el patrón moderno/colonial/capitalista/patriarcal de las relaciones económicas, políticas, sociales y culturales que dominan la vida, reconstruyendo otro tipo de vínculos donde primen la cooperación, la solidaridad y el respeto. Como señala García Guerreiro (2012: 183):

la solidaridad atraviesa la vida social en su conjunto, y la economía solidaria es entendida como un proceso económico, subjetivo y político a la vez. Siguiendo a Quijano, el sentido emancipador de estas propuestas puede encontrarse en que en las mismas se observan elementos como la re-emergencia de la reciprocidad (...); la comunidad como estructura de autoridad colectiva; la igualdad social de los individuos dentro de la diversidad y de la heterogeneidad de identidades individuales y colectivas; la horizontalidad de las relaciones entre los individuos de todas las identidades; las relaciones de uso $y$ de reproducción con los otros seres vivos; y una cultura de corresponsabilidad en la existencia del universo.

De las dos experiencias que analizamos, notamos que la Cooperativa Zuem Mapuche es la que mayormente se inscribe en esta visión. Desde sus orígenes y la forma en que es concebida -como respuesta a una problemática económica y social puntual, pero en el horizonte de una reflexión político-identitaria más general- esta organización promueve instancias de reflexividad de sus propias prácticas y un posicionamiento crítico del orden social que los margina en tanto poblaciones indigenas. La cuestión étnica atraviesa indisolublemente al colectivo, posibilitándole mantener una sólida coherencia entre su actividad económica -tanto en las comunidades rurales de origen como en la esfera de la comercialización en la ciudad- y la actividad de promoción y defensa de su identidad mapuche. De hecho, es notable que la actividad comercial se subsume a la lógica política en tanto las decisiones que se toman en la cooperativa tienen que ver primordialmente con esta defensa del "ser mapuche". Esto puede verse, por ejemplo, en que las decisiones acerca de lo que 
De Prácticas y discursos

Universidad Nacional del Nordeste

Centro de Estudios Sociales

Año 7, Número 10, 2018, Octubre

ISSN 2250-6942

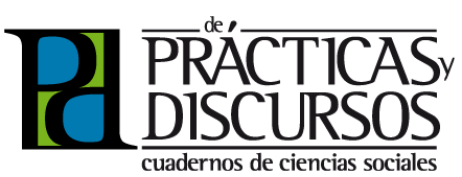

se va a producir -siempre respetando las formas tradicionales mapuche de hacerlo- o la forma en que se va a comercializar -a precios que permitan asegurar la justa retribución al trabajo, distinguiendo el origen de los productos, etc.-, así como la manera en que va a funcionar la propia cooperativa -con elección periódica de los representantes, con una estructura de organización democrática- se toman siempre colectivamente y responden a los intereses colectivos.

En este sentido podemos afirmar que la experiencia de la Cooperativa Zuem Mapuche es más cercana al ideal planteado por Coraggio (2011: 44) como "la posibilidad de desarrollar una socioeconomía, en que los agentes económicos no son escindidos de sus identidades sociales, mucho menos de su historia y de su incrustación en el mundo simbólico e institucional que denominamos cultura". Ciertamente, el mismo autor señala que la práctica económica, si forma parte de un proyecto de construcción de alternativas al capitalismo, no puede -o no debe- estar escindida de su fundamentación política.

Por su parte, el Mercado de la Estepa es una instancia de comercialización que podemos incluir entre las prácticas de la Economía Social, pero su horizonte de significación no es emancipatorio en los términos que propone Marañón. Por un lado, su surgimiento responde a inquietudes exógenas a los productores que se nuclean alli, siendo estos convocados por instituciones que luego asumirán un rol directivo y organizador casi excluyente. Asimismo, las decisiones sobre el qué y el cómo producir, las proyecciones de crecimiento de la asociación, sobre aspectos de la propia estrategia comercial - carteles, publicidad, estética-, los vínculos con otras organizaciones de la zona y con las propias autoridades municipales, no son discutidas en el seno del colectivo o en instancias que incluyan a los productores. Estos pobladores parecen estar involucrados exclusivamente en la propia tarea de producción y eventualmente en la atención del local comercial (exclusivamente los fines de semana).

No estamos abriendo un juicio de valor negativo acerca de esto. En realidad, consideramos que la organización ha significado posiblemente una mejoría substancial en las condiciones de venta de los productos, y el hecho de que ya lleve casi 20 años de existencia denota su accionar ventajoso para las comunidades. Sin embargo, y cito a Marañón (2012: 47), "la colonialidad del poder plantea una relación de interdependencia entre lo económico y lo político 
De Prácticas y discursos

Universidad Nacional del Nordeste

Centro de Estudios Sociales

Año 7, Número 10, 2018, Octubre

ISSN 2250-6942
PRÁCTICAS ECONÓMICAS HETERODOXAS, DECOLONIALIDAD Y ETNICIDAD. DOS EXPERIENCIAS MAPUCHE DE ECONOMÍA SOCIAL EN ARGENTINA

HETERODOX ECONOMIC PRACTICES, DECOLONIALITY AND ETHNICITY. TWO MAPUCHE EXPERIENCES OF SOCIAL ECONOMY IN ARGENTINA

emancipador, es decir que las formas económicas de control del trabajo basadas en la reciprocidad deben complementarse y reforzarse con una estructura política adecuada". Y la politicidad, para los pobladores mapuche, pasa fundamentalmente por la lucha reivindicativa de sus derechos como pueblo nación. La forma de vida tradicional de las comunidades indigenas, en general, implica el reconocimiento del valor de lo comunitario, de la autodeterminación y los vínculos de reciprocidad. Como apunta García Guerreiro (2012: 196), "[el] ejercicio colectivo de decidir, producir, resolver necesidades sociales o comunitarias, nutre la búsqueda por formas más democráticas y autónomas de producir y de vivir en sociedad", lo cual contribuye a la construcción de una sociedad más justa donde los derechos de todos y cada uno, pero sobre todo, de aquellos que fueron históricamente sojuzgados, sean respetados en su especificidad e integralmente.

\section{CONSIDERACIONES FINALES}

Las experiencias que hemos comentado en este trabajo constituyen claros exponentes de la Economía Social, mas sus especificidades nos alientan a pensarlos comparativamente, tomando el clivaje étnico como uno de los principales elementos diferenciadores. La introducción de las nociones de la decolonialidad no ha servido de disparador de una reflexión más profunda acerca de lo político que subyace a la economía que se despliega en los márgenes del capitalismo.

Y refiero nuevamente a Marañón (2012: 14), citando algunos de los interrogantes que sirven de horizonte en este planteo: "¿Es posible pensar en una economía alternativa sin una política y una subjetividad distinta?, ¿la economía solidaria es parte de una propuesta de transformación social?, ¿cuáles son las implicaciones teóricas de pensar esas experiencias económicas solidarias como parte de ese proyecto de transformación social?". No apuntamos a responder estas preguntas, pero sí nos sentimos interpelados a considerarlas cuando reflexionamos en torno a experiencias alternativas de producción y reproducción de la vida.

La Economía Social y Solidaria, como concepto y praxis, es una dimensión fundamental dentro de la reflexión acerca de los derechos de los pueblos a la identidad, la autodeterminación y autonomía de decisiones acerca de cómo quieren desarrollarse y vivir. $Y$ ese debate necesariamente debe incluir otros derechos 
como los de la naturaleza -en un contexto cada vez más amenazador para la misma- donde el hombre y la mujer son un componente más de un complejo y valioso sistema de relaciones. Las luchas de los pueblos en pos de sus derechos se expresan en múltiples formas y las experiencias económicas alternativas son una de ellas. Solidaridad, autonomía y emancipación en el centro de la escena enriquecen un prolífico debate.

BIBLIOGRAFÍA

BARTOLOMÉ, M.A. (1997). Gente de costumbre y gente de razón. Las identidades étnicas en México. México: INI-Siglo XXI Editores.

CECEÑA, A.E. (2004). Estrategias de construcción de una hegemonía sin límites. En Ceceña, A.E. (comp.) Hegemonías y emancipaciones en el siglo XXI. Buenos Aires: Clacso.

CORAGGIO, J.L. (2004). Una alternativa socioeconómica necesaria: la Economía Social. En Danani, C. (comp.) Política Social y Economía Social. Buenos Aires: UNGS/Altamira/Osde.

(2011). Economía social y solidaria. El trabajo antes que el capital. Quito: Ediciones Abya-Yala.

(2016). La economía social y solidaria (ESS): niveles y alcances de acción de sus actores. El papel de las universidades. En Puig, C. (org.) Economía Social y Solidaria: conceptos, prácticas y políticas públicas. Bilbao: Universidad del País Vasco/Hegoa.

COTERA, A. Y ORTIZ ROCA, H. (2009). Comercio Justo. En Cattani, A.; Coraggio, J.L. y Laville, J. (orgs.) Diccionario de la otra economía. Buenos Aires: UNGS-Altamira-Clacso.

GARCÍA GUERREIRO, L. (2012). Aportes para una economía para la vida, aprendizajes desde los mundos campesinos. En Marañón-Pimentel, B. (coord.) Solidaridad económica y potencialidades de transformación en América Latina: una perspectiva descolonial. Buenos Aires: Clacso.

GROSFOGUEL, R. (2006). La descolonización de la economía política y los estudios postcoloniales: Transmodernidad, pensamiento fronterizo y colonialidad global. Tábula Rasa, 4. Bogotá. 
De Prácticas y discursos

Universidad Nacional del Nordeste

Centro de Estudios Sociales

Año 7, Número 10, 2018, Octubre

ISSN 2250-6942
PRÁCTICAS ECONÓMICAS HETERODOXAS, DECOLONIALIDAD Y ETNICIDAD. DOS

EXPERIENCIAS MAPUCHE DE ECONOMİA SOCIAL EN ARGENTINA

HETERODOX ECONOMIC PRACTICES, DECOLONIALITY AND ETHNICITY.

TWO MAPUCHE EXPERIENCES OF SOCIAL ECONOMY IN ARGENTINA

KILLMEATE, R. Y SCHULZ, H. (2014). El mercado de la Estepa en la provincia de Río Negro, Argentina. Un mercado asociativo de las mesetas patagónicas. Voces en el Fénix, 38. Buenos Aires: Facultad de Ciencias Económicas, UBA.

LANDER, E. (2003). Ciencias sociales: saberes coloniales y eurocéntricos. En Lander, E. (comp.) La colonialidad del saber: eurocentrismo y ciencias sociales. Perspectivas latinoamericanas. Buenos Aires: Clacso.

MARAÑÓN-PIMENTEL, B. (2012). Introducción. En Marañón-Pimentel, B. (coord.) Solidaridad económica y potencialidades de transformación en América Latina: una perspectiva descolonial. Buenos Aires: Clacso.

MARAÑÓN-PIMENTEL, B. (2012). La colonialidad del poder y la economía solidaria. Apuntes para la reflexión teórico-metodológica del grupo de trabajo economía solidaria, CLACSO. En Marañón-Pimentel, B. (coord.) Solidaridad económica y potencialidades de transformación en América Latina: una perspectiva descolonial. Buenos Aires: Clacso.

MARX, K. (2008 [1867]). El Capital. Crítica de la economía política. Vol. 1 y 2. Buenos Aires: Siglo XXI Editores.

MELO LISBOA, A. DE (2004). Mercado solidario. En Cattani, A. (org.) La otra economía. Buenos Aires: Fundación Osde-Editorial Altamira.

MIGNOLO, W. (2007). La idea de América Latina. La herida colonial y la opción decolonial. Barcelona: Gedisa Editorial.

Polanyi, K. (1975). La gran transformación. Buenos Aires: Editorial Claridad.

QUIJANO, A. (2003). Colonialidad del poder, eurocentrismo y América Latina. En Lander, E. (comp.) La colonialidad del saber: eurocentrismo y ciencias sociales. Perspectivas comparadas. Buenos Aires: Clacso.

QUINTERO, P. (2012). Colonialidad del poder, comunidades indígenas y economías alternativas. Consideraciones sobre el indigenismo de los programas de economía solidaria. En Ma- 
rañón-Pimentel, B. (coord.) Colonialidad del poder, comunidades indigenas y economías alternativas. Consideraciones sobre el indigenismo de los programas de economía solidaria. Buenos Aires: Clacso.

SINGER, P. (2007). Economía solidaria. Un modo de producción y distribución. En Coraggio, J.L. (org.) La economía social desde la periferia. Buenos Aires: Altamira.

SMITH, A. (1990 [1776]). Investigación sobre la naturaleza y causa de la riqueza de las naciones. México: Fondo de Cultura Económica.

VUOTTO, M. (1994). Paradojas de la organización cooperativa. En Giarracca, N. (comp.) Acciones colectivas y organización cooperativa. Reflexiones y estudios de caso. Buenos Aires: Centro Editor de América Latina.

WALLERSTEIN, I. (1979). El Moderno Sistema Mundial. Vol. 1, 2 y 3. México DF: Siglo XXI Editores.

\section{FUENTES}

COOPERATIVA ZUEM MAPUCHE (2014). Cooperativa Zuem Mapuche [Mensaje en un blog]. Cooperativa Zuem Mapuche. Recuperado de http://cooperativazuemapuche.blogspot.com/p/ historia.html

S.A. (2018). ¿Qué es el mercado de la estepa? Argentina: Mercado de la Estepa Quimey Piuké: http://www.mercadodelaestepa.com.ar 